Henri Hytönen, Toni Jarimo, Ahti Salo, and Erkki Yli-Juuti. 2008. Markets for standardized technologies: patent licensing with Principle of Proportionality. Helsinki University of Technology, Systems Analysis Laboratory, Research Report E21.

(C) 2008 by authors 
Helsinki University of Technology

Systems Analysis Laboratory Research Reports

\section{MARKETS FOR STANDARDIZED TECHNOLOGIES: PATENT LICENSING WITH PRINCIPLE OF PROPORTIONALITY}

Henri Hytönen Toni Jarimo Ahti Salo Erkki Yli-Juuti 
Distribution:

Systems Analysis Laboratory

Helsinki University of Technology

P.O. Box 1100

FIN-02015 HUT, FINLAND

Tel. +358-9-4513056

Fax. +358-9-451 3096

systems.analysis@hut.fi

This report is available at www.e-reports.sal.hut.fi/pdf/E21.pdf

Series E - Electronic Reports

www.e-reports.sal.hut.fi

ISBN 978-951-22-9389-6

ISSN 1456-5218 
Title: $\quad$ Markets for standardized technologies: Patent licensing with Principle of Proportionality

Authors: Henri Hytönen

VTT Technical Research Centre of Finland

P.O. Box 1000, FI-02044 VTT, FINLAND

henri.hytonen@vtt.fi

Toni Jarimo

Nokia Corporation

P.O. Box 226, FI-00045 Nokia Group, FINLAND

toni.jarimo@nokia.com

Ahti Salo

Systems Analysis Laboratory

Helsinki University of Technology

P.O. Box 1100, 02015 HUT, FINLAND

ahti.salo@tkk.fi

www.sal.hut.fi/Personnel/Homepages/AhtiS.html

Erkki Yli-Juuti

Nokia Corporation

P.O. Box 100, FI-00045 Nokia Group, FINLAND

erkki.yli-juuti@nokia.com

Date: $\quad$ May, 2008

Status: $\quad$ Systems Analysis Laboratory Research Reports E21 May 2008

Abstract: This paper studies the licensing of standard-related patents owned by different companies. We examine a two-level licensing model where (i) the aggregated value of technology in the end product is shared among the relevant integrated technologies, and (ii) the value of each technology is shared among patent owners in proportion to the strength of their respective patent portfolios in these technologies. Moreover, we develop a system-dynamics simulation model for technology and product markets, and present numerical results which suggest that proportional sharing of licensing payments is viable in view of market growth, technology development and company profitability.

Keywords: standards, patents, licensing, proportionality, system dynamics. 


\section{Introduction}

Most technology-intensive industries have reached a state where the ownership of standardized key-technologies is spread among several companies. This situation is comparable to that at the beginning of the 20th century when a large number of companies held patents that were pivotal to the development of radio (Grindley and Teece, 1997). Today, companies like Alcatel-Lucent, Ericsson, Motorola, Nokia, Qualcomm, and Siemens - to name but a few - own patents that are essential to widely employed cellular telecommunications technology standards, such as GSM ${ }^{1}$ and UMTS $^{2}$ (Goodman and Myers, 2007).

Yet, the distributed ownership of patents entails the risk of a deadlock where patent owners make it commercially infeasible to develop products that utilize standardized technologies. This type of market failure - where rational individuals do not fully exploit a scarce resource - is called the tragedy of the anticommons (Heller, 1998), as a counterpart to the well-known tragedy of the commons which refers to situations where scarce resources are overexploited (Hardin, 1968). In technology-intensive industries, the tragedy of the anticommons is harmful because it causes inefficiencies in the use of available technologies, lack of profitability of further technology development, and even suppression of innovations (Calderini and Giannaccari, 2006; Shapiro, 2006; Takalo and Kanniainen, 2000). Indeed, these social costs may outweigh the benefits of the patent system (Hall and Ziedonis, 2001). Evidence on the related harmful consequences have been reported for instance through studies on biomedical research (Heller and Eisenberg, 1998), semiconductors (Ziedonis, 2004), and scientific research at large (Andrews et al., 2006).

To avoid the tragedy of the anticommons, companies that participate in the standards development usually agree to license the patents that are necessary for using the standard. These licensing commitments support the adoption of open standards and allow

1 Global System for Mobile Communications

2 Universal Mobile Telecommunications System 
companies with strong patent portfolios to gain a competitive advantage through an improved net licensing structure (Shapiro, 2001). Moreover, because patent portfolios have accumulated from investments into standards development, it is fair that the companies that have invested more heavily should also be able to benefit from the resulting patents; otherwise, the benefits from investments into technology development become questionable (cf. Teece, 1986).

In the traditional licensing model, the licensee pays a fixed percentage of its turnover to the licensor. Yet this model, combined with prevailing trends in the distribution of patent ownership and the integration of multiple technologies into one product, has given rise to a new problem: the cumulative licensing fees are reaching levels where it is becoming unprofitable to manufacture products with many integrated technologies (Bekkers et al., 2002; Lemley and Shapiro, 2007; Thumm, 2005). An example of a common multitechnology product with widely distributed patent ownership is the multi-mode mobile handset with digital camera and wireless local area network (WLAN) interface.

In this paper, we study the impacts of different royalty payments that are set according to the Principle of Proportionality (Frain, 2006) in two stages. First, the values of different technologies are estimated based on the customer-perceived value of the integrated product, with the aim of determining a reasonable level for the aggregated royalty payments for each technology. Second, the license fees for the patent portfolio of a single patent owner are calculated as shares of these aggregated royalty levels: that is, because the technology is owned by several companies, the value that it yields is shared among the companies in proportion to the respective strengths of the companies' patent portfolios. This licensing model avoids the problem of excessive royalty stacking, because the aggregated value of integrated technologies cannot exceed the total technological value of the product; it is Fair, Reasonable, and Non-discriminatory (FRAND) as requested by typical licensing policies of the standard setting organizations (e.g. ETSI, 2006a).

Specifically, we present a system dynamics model of technology and product markets based on the proportional licensing regime. This model allows us to study the emergence 
of product markets, as well as the profitability of different kinds of companies under the licensing regime. As a result, the model highlights key issues in licensing and offers insights to support policy making, too. Indeed, because standards and licensing policies are inherently systemic instruments (Smits and Kuhlmann, 2004), they need to be seen within the broader techno-economic landscape (Salmenkaita and Salo, 2002, 2004) which, in turn, can be examined through the conceptual and modeling tools of system dynamics (Sterman, 2000, 2001).

The rest of this paper is organized as follows. Section 2 describes the characteristics of technology and product markets and poses the research questions. Section 3 presents the system dynamics model for the study of these markets in Section 4. Section 5 discusses the validity and limitations of our study, and Section 6 concludes with policy implications.

\section{Technology markets}

\subsection{Technology standardization and patents}

Standardization seeks to ensure the interoperability of products. Traditionally, this has been achieved through the standardization of open interfaces (e.g. air interface between the mobile handset and the base station). In communication technologies, in particular, the interoperability of products is crucial for the attainment of network effects (Gandal et al., 2003) that materialize when the value of using a product or service increases with the total number of users. In this way, the development of standards supports the creation of healthy product markets for component manufacturers, device manufacturers, and telecommunication operators. The consumers, in turn, may benefit from the competition between alternative standards.

Standards are established by standards development organizations (e.g. ETSI, 3GPP, OMA, and IETF in the telecom industry) whose activities build on the contributions of 
the participating companies. During the development phase, the contributing parties invest in technological development and create patent rights as a result of this investment. The patent rights give the owners the right to exclude others from using the patented invention, subject to the uncertainties of patent litigation processes (Lemley and Shapiro, 2005). Yet, the possibility of excluding others contradicts the objective of ensuring interoperability, which was the objective of the participants of the standardization process in the first place.

To avoid complications due to mutual exclusion, the standardization organizations require their participants to subscribe to a policy which defines rules for the licensing of patents that are essential to the standard. Hence, the participants are faced with a trade-off between (i) retaining the rights to proprietary technology for their own use only, and (ii) making this technology more broadly used, thus facilitating its wider adoption (Blind and Thumm, 2004; West, 2003). Examples of licensing policies include, for instance, FRAND and Royalty Free (RF) (Dolmans, 2002). The lengths of licensing contracts are typically for a limited period of time or until the patents that have been filed before the specified date expire.

Specifically, standards development organizations ask developers to declare which of their patents are essential to the standard. Essentiality of patents, or intellectual property rights (IPR), is defined as follows (ETSI, 2006b):

"ESSENTIAL" as applied to IPR means that it is not possible on technical (but not commercial) grounds, taking into account normal technical practice and the state of the art generally available at the time of standardization, to make, sell, lease, otherwise dispose of, repair, use or operate EQUIPMENT or METHODS which comply with a STANDARD without infringing that IPR. For the avoidance of doubt in exceptional cases where a STANDARD can only be implemented by technical solutions, all of which are infringements of IPRs, all such IPRs shall be considered ESSENTIAL.

The definition implies that, through injunction, the ownership of one essential patent suffices to prevent the implementation of a standard. Thus, essential patents yield con- 
siderable negotiation power.

\subsection{Proportional sharing of standardization benefits}

Because the standards are available to all companies - regardless of their contributions to standardization work - there is a need for additional incentives for them to contribute. First, participation allows companies to create early knowledge, which helps them in market entry. Second, technology developers can accumulate patents on standardized technologies, meaning that after bilateral licensing agreements, companies with strong patent portfolios tend to become net gainers while those with weaker patent portfolios tend to become net payers. Thus, because companies with strong patent portfolios have usually invested more heavily into technology development, the licensing agreements provide a risk premium for the investors.

From the perspective of a healthy business environment, the licensing framework should fulfill three conditions. First, the system should ensure that the cost of licensing does not preclude the adoption of technology. Second, the royalty level should be predictable enough to support the planning of technology development and productization investments. Third, the system should establish incentives for companies to invest in technology development. In recognition of these conditions, ETSI (2006a), for example, requires its members to license standardized technology under FRAND terms.

Frain (2006) describes a FRAND licensing model where the royalty payments are determined using the Principle of Proportionality. According to this principle, the technological value of products is shared among the patent owners in proportion to the strengths of their patent portfolios, as measured by the number of patents that are essential to the technology concerned. For example, if Company $X$ owns $30 \%$ of the patents that are declared essential to UMTS standard, and the value of the UMTS technology in a mobile handset is set at $5 \%$ of the price, then $X$ is entitled to royalties that amount to $5 \% \cdot 30 \%=1.5 \%$ of the price of each handset (see Figure 1). 


\section{Please insert Figure 1 about here}

More formally, the Principle of Proportionality in patent licensing is defined as follows (Frain, 2006) :

PROPORTIONALITY. Compensation under FRAND must reflect the patent owner's proportion of all essential patents. This is not simply a numeric equation but the compensation must, within reasonable bounds, reflect the contribution.

The rule of proportionality is the most common utility-sharing rule in business (Thomson, 2003). For instance, the usual way to share profits from a joint venture is in proportion to the companies' investments to it. Thus, Frain's (2006) proposition for compensation based on contribution is well-aligned with widely accepted principles.

Proportional utility-sharing rules have been axiomatized by Kalai (1977) and Roth (1979) in game theoretic terms. In a seminal paper, Kalai (1977) shows that proportional solutions satisfy the step-by-step negotiation property. In the standardization context, this property means that companies can share the value of each technology separately, whereafter the resulting shares over all technologies will be the same as if the shares were agreed upon through a single aggregate negotiation over all technologies: in fact, proportional sharing is the only sharing rule that satisfies the axiom of step-by-step negotiation. This is important also for the practical organization of negotiations, because not all companies employ all standards in their products. Thus, if the axiom of step-bystep negotiation (and hence the proportionality principle) were abandoned, there would be a need to build a very large consortium that would have to agree on all standards, thus ensuring that the order of topics on the negotiation agenda would not influence the outcome. However, in practice it is impossible to build and manage consortia of such size. Step-by-step negotiations also ensure that the same proportional shares remain valid when the markets grow. 


\subsection{Players of the technology and product markets}

The companies that take part in the development and utilization of standards can be categorized as follows:

- Patenting and Manufacturing Companies (PMC) are companies that contribute strongly to technology and standards development and manufacture and sell related products.

- Manufacturing Companies (MC) manufacture and sell their own products, but make small investments in technology and standards development in comparison with the size of their product sales.

- Patenting Companies (PC) contribute to technology and standards development, but have small or negligible product sales in comparison with their patent portfolios.

For example, Table 1 shows the estimated market shares of companies that sell products based on UMTS standards. The table also shows the ownership of patents that were judged essential to UMTS technology, according to Goodman and Myers (2005).

\section{Please insert Table 1 ABOUt here}

PMCs drive the creation of new technologies. They invest heavily in R\&D and have a strong influence on emerging standards. Usually, they are the first to introduce new products, which is how they obtain most value from technology development. PMCs have two-fold objectives in licensing: on one hand, they seek to minimize the license costs due to licenses from third parties; on the other hand, they seek income from companies that have no patents by licensing their own patents to these companies.

MCs adopt the follower strategy as they let others develop the technology and focus on the implementation of the open technology. Their R\&D investments are much lower than those of PMCs. MCs extract value only through product sales, and seek to minimize the compensation to the patent owners. 
PCs with no product sales are an increasing trend (see e.g. Arora et al., 2001). They protect the results of their $\mathrm{R} \& \mathrm{D}$ work and contribute to the standardization process with the aim of making profits by licensing their patents to PMCs and MCs. Usually, these companies seek to maximize the value of the technology in the product markets, as well as their own share of this value.

\subsection{Research objectives}

In the Principle of Proportionality regime, the dominant factor that influences the companies' share of income from product and technology markets is the technological value (or costs) of a single technology, as illustrated in Figure 1. The cost of technology depends on the stacking of technologies and growing R\&D investments, and it is reflected in the increased royalty rates that are paid by the licensees. In this setting, we seek to answer the following questions:

Q1: How does the technology royalty rate influence the companies' actions and profits under the Principle of Proportionality?

Q2: Under Principle of Proportionality, how does the technology royalty rate influence the growth of product markets?

We address these questions with a simulation model that combines key aspects of technology development, licensing agreements, and product sales. Based on system dynamics (e.g. Sterman, 2000, 2001), our model helps project the profitability of companies (Q1) and the growth of product markets (Q2) as a function of the cumulative royalty rate. This model has been built in close collaboration with experts who are active in standards organizations. It has been validated by running extensive sensitivity analyses on the model parameters.

To our knowledge, system dynamics has not been previously applied to study how the cost of technological standards impacts the pace of technology development and the emergence of product markets in the presence of different kinds of companies. Yet system 
dynamics seems a suitable approach, because it helps capture nonlinear dependencies among variables that pertain to the behavior of companies and markets alike. The resulting models can be quite comprehensive and transparent, and can thus offer valuable insights for decision and policy making.

\section{System dynamics model of technology markets}

\subsection{General model structure}

Our model of product and technology markets has five modules (Figure 2) (a detailed illustration of the model is in Appendix C). The module for Technology Development describes the impact of $R \& D$ investments on the cumulative level of intellectual capital, on one hand, and the linkage between the cumulative intellectual property and the companies' patent-portfolio strength in licensing negotiations, on the other hand. The module for Product Market Dynamics describes the emergence of product markets. The development and attractiveness of these markets depends, in part, on the companies' R\&D investments, which increase the attractiveness of the product markets. If the final products are not attractive enough, the markets may fail to emerge. Moreover, the success of product markets depends on the product manufacturers' initial marketing investments towards the creation of large enough markets.

Please insert Figure 2 about here

Companies obtain their income either from product business, licensing income, or both. The product business income depends on the product market dynamics, the timing of market entry, and the competitive position of the company. A fraction of this income from product business is paid as licensing income by way of royalty payments to the companies that own patents for the products sold. Finally, the income, development costs, and licensing cost all have an impact on profitability. Profitability influences the companies' product manufacturing decisions and hence product market dynamics, too. 
In the product and technology markets, there are three kinds of companies who acquire their profits through strategically different mechanisms. Thus, our model has three companies; one from each category. Final products are manufactured by the PMC and the MC, who both obtain a major part of their income from the product business. The PMC and the PC together own the patents for standardized technologies that are embodied in final products. They both get additional income from licensing agreements. This categorization is well in line with the ideas of Kunc and Morecroft (2007), who suggest to focus the modeling efforts on the rivalry of conceptually different companies.

The amount of income (costs) that a company receives (pays) due to licensing contracts depends on the strength of its patent portfolio in relevant technologies. Because $\mathrm{R} \& \mathrm{D}$ investments and product manufacturing generate costs, the PMC and the MC will initiate manufacturing and sales activities only after they expect to gain profits. The profitability of the different companies is measured by accounting for the net present value (NPV) of manufacturing and licensing cash-flows.

We are mainly interested in the qualitative behavior of product and technology markets, as well as the relative levels of corresponding variables, rather than the absolute levels of these variables. In consequence, we employ parameter values that represent the stylized features of the market. The variables and the parameter values are listed in Appendices $\mathrm{A}$ and $\mathrm{B}$, respectively.

\subsection{RED activity as an accelerator of patent portfolios}

The technology level and the companies' patent-portfolio strengths are based on investments into research and development. The dynamic dependencies between R\&D investments, cumulative R\&D, and patent-portfolio strengths for the PMC and the PC are shown in Figure 3. R\&D investments $i(t)$ increase the cumulative R\&D level of the company, denoted by $T(t)$, which is assumed to be proportional to the strength of the company's patent portfolio. This assumption seems plausible, because several stud- 
ies show that there is a high correlation between R\&D and patenting indicators. The correlation between R\&D and lagged patenting indicators is particularly significant, although the immediate impact of R\&D on patenting may be small (see e.g. Hall et al., 1986; Scherer, 1965). Some studies on the relationships between R\&D activity and company profitability/market value have employed $R \& D$ expenditures as a proxy for later strength of cumulative R\&D. This is often measured in terms of the number of patents that are granted to the company (see e.g. Greenhalgh and Rogers, 2006; Lin et al., 2006).

\section{Please insert Figure 3 ABout here}

Due to technology development, part of the cumulative patents related to the technology become obsolete. Our model captures this phenomenon by assuming that the cumulative R\&D level (and hence the patent-portfolio strength of a company) diminishes at a rate that is proportional to the cumulative royalty level. For example, Greenhalgh and Rogers (2006) suggest $15 \%$ or $20 \%$ annual depreciation for returns on R\&D, which would correspond to technology half-life of roughly 3 to 4 years.

The dynamics of the cumulative technology and patent-portfolio strength $T(t)$ for PMC can now be written as

$$
\frac{d T_{P M C}(t)}{d t}=i_{P M C}(t)-\frac{T_{P M C}(t)}{\tau_{T L C}}
$$

where the parameter $\tau_{T L C}$ specifies the length of the technology life cycle (i.e., the rate at which cumulative $R \& D$ becomes outdated). Specifically, $\tau_{T L C} \cdot \ln 2$ is the time within which half of the developed technology becomes obsolete. The dynamics for the PC are identical.

To apply the Principle of Proportionality to the calculation of licensing payments, we need to determine the relative strengths of the companies' patent portfolios. Because the strengths of patent portfolios are assumed to be proportional to the cumulative R\&D levels, and all patents that relate to the given technology are owned by the PMC and the PC, the strength of the PMC's patent portfolio is $\gamma_{P M C}(t)=T_{P M C}(t) /\left[T_{P M C}(t)+\right.$ 
$\left.T_{P C}(t)\right]$. This case for the PC is similar.

Results from the technology development module are illustrated in Figure 4 which shows simulation results of the development of cumulative R\&D and the desirability of technology using parameter values listed in Appendix B. Here, the investment rate into technology development is constant for the PMC and the PC alike. The cumulative R\&D levels in the upper graph correspond to the patent-portfolio strengths of the patent owners. The concave shape of the graphs is due to the expiration rate of technology which increases as the size of the portfolio grows and thus diminishes the growth rate.

\section{Please insert Figure 4 ABOUt here}

The lower graph of Figure 4 shows the development of the desirability of technology in the markets for final products. In the simulation, the desirability of technology, $\beta_{\text {tech }}(T)$, is an S-shaped function of total cumulative R\&D investments. This reflects the fact that substantial efforts are needed before interoperable standards can be formed and competitive products manufactured. Furthermore, when the technology is mature enough, additional technological development yields little additional value to the final products.

\subsection{Product market dynamics}

Our product-markets model is analogous to the Bass (1969) model of consumer durables where potential customers $P(t)$ become customers $C(t)$ by purchasing the product (see Figure 5).

\section{Please insert Figure 5 about here}

Potential customers' propensity to buy the product depends on two mechanisms, the innovation effect and the imitation effect. That is, the amount of sales through innovation or advertising-type effects is proportional to the number of potential customers, while the imitation or word-of-mouth-type sales are proportional to the product of potential and actual customers. As a modification of the basic Bass model, the products' attractiveness 
depends on the desirability of the technology, which depends on the accumulated R\&D investments by the PMC and the PC.

Furthermore, it is assumed that the total sales on the product market depends on the number of companies operating in it. When only the PMC or the MC is in the market, smaller variety of products are manufactured and thus the total sales level will be lower than when they both are active in the market.

Products that utilize the technologies can become obsolete and must thus be replaced. This means that customers who have bought the product earlier on are likely to become potential customers again. The dynamics of potential customers $P(t)$ and actual customers $C(t)$ is modeled through

$$
\begin{aligned}
& \frac{d P(t)}{d t}=\frac{C(t)}{\tau_{P L C}}-s_{P M C}(t)-s_{M C}(t) \\
& \frac{d C(t)}{d t}=s_{P M C}(t)+s_{M C}(t)-\frac{C(t)}{\tau_{P L C}},
\end{aligned}
$$

where $\tau_{P L C}$ is the product life cycle length parameter (i.e., $\tau_{P L C} \cdot \ln 2$ is the average time in which half of current customers turn to potential customers again). The instantaneous sales rates $s_{P M C}(t)$ and $s_{M C}(t)$ are given by

$$
\begin{aligned}
s_{P M C}(t)= & \delta_{P M C}(t)\left[m-\Delta m \delta_{M C}(t)\right] . \\
& {\left[\beta_{\text {tech }}\left(T_{P M C}(t)+T_{P C}(t)\right)\right]\left[\beta_{a d v} P(t)+\beta_{\text {imit }} P(t) C(t)\right] . }
\end{aligned}
$$

The corresponding sales level equation $s_{M C}(t)$ for the $\mathrm{MC}$ is similar (here, $\delta_{P M C}(t)$ and $\delta_{M C}(t)$ are indicator variables for the PMC's and the MC's product market activity, i.e., $\delta_{P M C}(t)=1$ if the PMC is active in the product market at time $t$, and 0 otherwise).

Parameter $m$ captures how efficiently companies can utilize the potential sales which results from technology maturity and innovative and imitative behavior of customers. Moreover, $\Delta m$ is the influence of the other company's market entry on the sales efficiency of the incumbent. For instance, when the PMC is the only player in the product market, the utilization of the sales potential equal $m$, and when the $\mathrm{MC}$ enters the market, the 
PMC's utilization drops to $m-\Delta m$. In the simulations, values of 0.75 and 0.25 were used for $m$ and $\Delta m$, respectively. This means that when single company is active in the market, the utilization of the sales potential will be $75 \%$, and when both manufacturers are active, the combined utilization will be $100 \%$ with both companies having equal $(50 \%)$ market shares.

The coefficients $\beta_{t e c h}, \beta_{a d v}$, and $\beta_{\text {imit }}$ in equation (2) refer to the attractiveness of technology and the impacts of innovative customer behavior and imitative customer behavior on sales, respectively. The technological attractiveness, which depends on companies' total cumulative R\&D investments, has a multiplicative impact on sales. Thus, sufficient development of technology is essential for the product markets to emerge.

The dynamics of product markets are illustrated in Figure 6, simulated with the parameters in Appendix B. The upper graph shows the timing of market entry and the sales for the PMC and the MC. In this example, the PMC enters the market first at month 24. Here, the net effect of the licensing agreement is that the PMC has a lower cost of technology and also an advantage over the $\mathrm{MC}$ when entering the market. When the market becomes large enough, it becomes profitable for the MC to manufacture its own products (even when licensing payments are accounted for), and thus the MC enters the market at month 44. At the same time, the entry of the competitor causes a drop in the PMC's sales. When both the PMC and MC are in the product markets, their sales levels develop in a similar way, because these two companies were assumed to achieve equal market shares in the example simulation.

\section{Please insert Figure 6 about here}

The lower graph of Figure 6 shows the development of the sales potential due to advertising and imitation, represented by dotted and solid lines, respectively. When there are no customers, the total sales potential comes only from advertising. When the first product manufacturer enters the market, the customer base begins to grow and the imitation effect, which depends multiplicatively on the levels of current and potential customers, starts to rise and becomes rapidly the dominant effect driving the sales behavior. 


\subsection{The companies' costs and profitability}

The companies' profitability depends on sales revenue, royalty payments, and costs of technology development and product sales. The income of the PMC and MC is based on product revenues, while the patent owners (the PC and the PMC) get income indirectly through product manufacturers' royalty payments. For the manufacturers, the profit is simply the sales revenue, or the level of sales multiplied by product price less the costs of manufacturing and royalty payments. For the patent owners, the profit is the received royalty payments minus the $R \& D$ expenditures. Because one of our central research questions was to compare the profits between companies with different patenting strategies, the product prices and manufacturing cost structures of the PMC and the PC were assumed equal.

The technology royalty rate $\xi$ determines the cost of the technology in the product; specifically, for each product sold, a fraction $\xi$ of the product price $p$ is paid to technology owners. The total royalty payment per product is divided among the patent owners according to their relative patent-portfolio strengths. Therefore, for example, for each product that the $\mathrm{MC}$ sells at time $t$, an amount $\xi p$ is paid to patent owners (i.e., $\xi \gamma_{P M C}(t) p$ is paid to the PMC and $\xi \gamma_{P C}(t) p$ to the PC). The resulting profit flows $\pi(t)$ at time $t$ are

$$
\begin{aligned}
\pi_{P M C}(t) & =\left[1-\xi \gamma_{P C}(t)\right] p s_{P M C}(t)+\xi \gamma_{P M C}(t) p s_{M C}(t)-c_{P M C}(t) \\
\pi_{M C}(t) & =[1-\xi] p s_{M C}(t)-c_{M C}(t) \\
\pi_{P C}(t) & =\xi \gamma_{P C}(t)\left[p s_{P M C}(t)+p s_{M C}(t)\right]-c_{P C}(t)
\end{aligned}
$$

where the companies' manufacturing and $\mathrm{R} \& \mathrm{D} \operatorname{costs} c(t)$ are

$$
\begin{aligned}
c_{P M C}(t) & =u s_{P M C}(t)+\tilde{\delta}_{P M C}(t) f+i_{P M C}(t) \\
c_{M C}(t) & =u s_{M C}(t)+\tilde{\delta}_{M C}(t) f \\
c_{P C}(t) & =i_{P C}(t) .
\end{aligned}
$$

Here, $u$ and $f$ are, respectively, the manufacturers' unit cost per product and fixed cost 
per unit time. The PMC and the PC can decide their market entry times $t_{P M C}$ and $t_{M C}$ independently; the market entry decision indicator $\tilde{\delta}_{P M C}(t)$ changes from 0 to 1 when the decision to enter the market is made. The actual sales can start after the decision to enter the product market is made and time $\tau_{M C}$ or $\tau_{P M C}$ needed to start manufacturing has passed, while the fixed costs of product manufacturing start to accrue from the decision point onwards. The manufacturing activity indicator is thus related to the market entry decision indicator through $\delta_{P M C}(t)=\tilde{\delta}_{P M C}\left(t-\tau_{P M C}\right)$.

Figure 7 gives an example of the development of the net cash flows $\pi(t)$, based on the parameters in Appendix B; here, the PMC enters the markets $t_{P M C}=22$ and the $\mathrm{MC}$ at $t_{M C}=34$. Early on, when no products are manufactured, the only cash flows are due to the technology development activities of the PMC and the PC. When manufacturing is started, the productization costs and the fixed manufacturing costs precede product sales, which causes a drop in the PMC's and the PC's cash flows at months 22 and 34, respectively. When product sales start, the PMC's net cash flow increases by the profit from product sales at month 24, and the PMC and the PC begin to receive licensing payments. The longer interval between the MC's market entry decision and actual market entry at month 44 is because the MC has not made previous investments to the development of the technology so that it needs more time to utilize the technology in final products.

Please insert Figure 7 about here

Based on profit flows, the net present value of the chosen strategy for the PMC can be calculated by using a discount rate $r_{P M C}$ as

$$
N P V_{P M C}=\int_{t_{0}}^{t_{f}} e^{-r_{P M C} t} \pi_{P M C}(t) d t
$$

and similarly for the MC and the PC. The possibility of different discount rates for the PMC, MC, and PC is motivated by the companies' different risk-positions. The MC faces risks that relate only to the product business. Similarly, the risks of the PC are driven 
by the investments that it has made into technology development; moreover, the PC can decrease its risk by licensing its patents to various other product markets, too. The PMC, in turn, has to invest both in the technological development and in the product business, and thus needs to cater for the risks related to both fields. In the example simulation, discount rates of 15,12 , and 20 percent were used for the MC, the PC, and the PMC, respectively (see Appendix B).

\subsection{The companies' market-entry decisions}

The market entry decision indicators $\tilde{\delta}_{M C}(t)$ and $\tilde{\delta}_{P M C}(t)$ are determined according to a non-cooperative game-theoretic approach. The decision variables of the PMC and MC are their market-entry timings while the outcomes are the resulting net present values calculated from (3). Both companies optimize their behavior against the other one, which generates the reaction curves $t_{M C}^{*}\left(t_{P M C}\right)$ and $t_{P M C}^{*}\left(t_{M C}\right)$, respectively, for the optimal market-entry times $t_{M C}^{*}$ and $t_{P M C}^{*}$ as a function of the other company's market-entry time. If both companies act rationally (in that they seek to maximize their NPVs) and choose their strategies simultaneously, the Nash equilibrium point for market entry times is at the intersection of these reaction curves (Başar and Olsder, 1982; Nash, 1951). At this intersection point, neither company would wish to change its entry time decision unilaterally.

Figure 8 illustrates the companies' NPVs with different market-entry times and corresponding reaction curves. The NPV contours in the figure are drawn with an $8 \%$ royalty rate, with horizontal axis representing the market entry of the $\mathrm{MC}$ and the vertical axis the market entry of the PMC. A lighter color in the contours represents a higher resulting NPV. The horizontal and vertical curves are the reaction curves of the PMC and the MC, respectively, and their intersection point is the resulting Nash equilibrium. In this illustration, the resulting market-entry times for the PMC and the MC would be $t_{P M C}^{*}=21$ and $t_{M C}^{*}=26$, respectively. 


\section{Simulation results}

\subsection{Technology royalty rate and companies' profitability}

In the model, the technology royalty rate represents the cost of technology as a percentage of the end-product price. Furthermore, estimates on the royalty levels have an impact on the companies' profit and risk forecasts. Therefore, it is of interest to examine various impacts of the royalty rate and to compare the success of different patenting strategies. The most important impact measure is the NPV of the companies' cash flows (3).

With our simulation model, we calculated the Nash-equilibrium market-entry times and the resulting profits with different technology royalty-rates (Figure 9). The results are as follows.

- At average royalty levels, the returns from the technology and product markets yield positive returns to all three companies. With the current parameter-values, the PMC's profitability is maximized at about $13 \%$ royalty rate.

- At low royalty levels $(<8 \%)$, the MC strategy becomes more profitable than the PMC strategy. In this case, PMC will opt for a pure manufacturing strategy, meaning that new technologies are developed less intensively and that product markets based on new technologies will emerge slowly, if at all. Similarly, the PC does not profit from investments into technology development, stops the investments, and the emergence of product markets will suffer.

- At high royalty levels $(>16 \%)$, the PC will earn greater profits than the PMC. This causes the PMC to switch to pure patent owner strategy while the MC exits the markets, which again disrupts the emergence of product markets. 


\section{Please insert Figure 9 about here}

The high and low levels of royalty rates are not absolute; rather, they are related to the cost structure of technology development and product sales in the examined market. For example, Megantz (2002) notes that across all industries, licensing agreements between $3 \%$ and $5 \%$ are most common, and that licensing royalty rates in excess of $10 \%$ are rare. However, in e.g. software products, royalty rates as high as $50 \%$ are not unheard of.

\subsection{Product-market dependencies on technology royalty rate}

The cost of technology has the following impacts on the companies' market-entry decisions (Figure 10) and on the size of the market (Figure 11).

- The time of market entry is deferred when the royalty rate increases. At low royalty rates, both the $\mathrm{MC}$ and the $\mathrm{PMC}$ enter the markets as soon as possible. At higher levels, the royalty rate has more influence on the MC than on the PMC. When the cost of technology is very high (16\% in the simulation), the MC will not adopt the technology at all.

- The cumulative sales decrease with increasing royalty rates. At very low royalty rates, product markets emerge quickly and are profitable for the PMC and the MC who both enjoy high cumulative sales. At low or average level, the royalty rate has a small impact on cumulative sales. At high levels of royalty rate (16\%), product manufacturing becomes unprofitable for the MC. Beyond this point, it is only the PMC that can act profitably in the product markets.

In summary, our model suggests that negligible or very high royalty rates are not optimal to any company. First, if royalty rates are too low, the PMCs are not compensated enough for their development effort and hence lose their competitive advantage against the MCs. This discourages technology development, suppressing the emergence of new product 
markets which the MCs could enter. Second, too high royalty rates lead to conditions where it is unprofitable to operate in the markets. Hence, the product markets die, the MCs lose their business and the PCs miss their royalty income. Therefore, licensingpolicy discussion should focus on finding principles that keep the royalty rates at viable levels.

\section{Please insert Figures 10 AND 11 ABout here}

\section{Discussion}

\subsection{Model validity}

Because our model has a large number of parameters, we tested the validity of the above key conclusions through extensive simulation runs based on different parameter values. As an example of one of these runs, Figure 12 shows how the companies' profits depend on the three market environment parameters $\beta_{a d v}, \beta_{\text {imit }}$, and $\beta_{\text {tech }}$. Each $\beta$-parameter varied over the uniform distribution $[0.9 \beta, 1.1 \beta]$ relative to its nominal value (i.e., $10 \%$ increases and reductions).

\section{Please insert Figure 12 ABout here}

As Figure 12 shows, the profits of the MC and the PC are rather insensitive to small variations in market conditions while that of the PMC is more sensitive. This is because if the markets are smaller than expected, the PMC will lose income through both technology ownership and own product sales. Similar sensitivity analyses were performed with regard to other model parameters, too. Overall, the model is more sensitive to parameters that influence the behavior of the first product-market entrant, while the parameters that influence later entrants are less significant. The impact on the profitability of the first-mover will delay the emergence of the product market as a whole, while the impact on the second-mover is limited to its profitability. 
Our system-dynamic simulation model could be extended in several ways. First, the companies' pricing logics could be enhanced by introducing dynamic control strategies: for instance, companies may seek to gain market share through price reductions, or to optimize their total profits in terms of volume and price. Second, our model does not account for discontinuities in the companies' behavior that could be caused by extreme royalty rates: for instance, the technology developers could discontinue their R\&D investments, or patent holders might refuse to sell licenses. However, to the extent that qualitative conclusions are consistently supported by simulations with non-extreme parameters, these discontinuities need not be explicitly modeled. This seems to be the case in our model: even with non-extreme royalty rates, the product markets would become unprofitable with very low or very high cumulative royalty rates.

In conclusion, our model appears valid for the purpose of gaining instructive insights. In particular, this model shows technology markets evolve through a complex dynamics that involves major nonlinearities: thus, in comparison with this approach, micro-economic modeling based on closed-form mathematical solutions would necessitate unrealistically simplistic assumptions. The parameters of our simulation model can also be estimated based on evidential data (rather than expert judgments), although it might be difficult to produce reliable estimates on the relevant cost structures, patent portfolios, and consumer preferences.

\subsection{Licensing agreements in practice}

In the implementation of the Principle of Proportionality, the valuation of technologies is a difficult but necessary step. Consider, for instance, a multi-mode mobile handset at a cost of $400 €$ based on UMTS, WLAN, and digital camera technologies. According to the Principle of Proportionality, the values of these different technologies would be shared among the technology owners in proportion to the strengths of their respective patent portfolios. But the valuation of these technologies (say, UMTS in a mobile handset) is not straightforward: although some estimates can be based, say, on costs or perceived 
customer value, this value must be ultimately set through negotiations, in terms of FRAND.

The negotiation results will depend on the disagreement points of the negotiating parties and their negotiation power. Here, a company with high exposed revenue has usually less negotiation power than a company with no exposed revenue. Exposed revenue is normally related to product sales, which the patent owner is able to forbid in case of disagreement (Shapiro, 2006; Teece, 2000). A risk is that essential patents may give their owners an unfair bargaining position in relation to their contribution to standards development, in particular if injunctive reliefs were available for essential patents too.

Despite the possible (and surmountable) difficulties of valuing technologies, the Principle of Proportionality offers many advantages. First, when technologies are valued as shares of the end-product value, the total licensing payments will remain reasonable. Second, the policy is fair for technology developers, as each new patent results in an increased compensation to its owner. Third, assuming the information on patent portfolios is common knowledge, the calculation of royalty payments is transparent.

\section{Conclusions}

Multinational companies in many high-technology industries are involved in patent disputes that concern flat displays, imaging devices, digital cameras, and telecommunications equipment, among many other products. Arguably, these industries would benefit from licensing policies that serve to mitigate problems of high legal expenses and risks of technological stagnation.

In this paper, we have developed a system-dynamics model for the study of a two-level policy that complies with the Fair, Reasonable, and Non-discriminatory (FRAND) terms of licensing. In this model, different technologies of the end product are valued based on their contribution to the aggregate value of technology in the end product. Second, the corresponding compensations to technology owners are calculated in proportion to the 
strengths of their respective patent portfolios (Frain, 2006).

While our model has been motivated mainly by telecommunications products, analogous models can be readily developed for other technology-intensive industries, too. Such models can be useful for studying how the cost of technology impacts the cash flows of different companies. In effect, these other impacts involve complex interdependencies that are not readily captured by less formal approaches. In addition, the development of models based on system dynamics offers a transparent approach for communicating key conclusions to decision and policy makers.

As a major policy implication, our results suggest that the two-level licensing model can help identify royalty rates that should be acceptable to all parties, in the sense that they ensure conditions for healthy product markets and incentives for technology development and innovation. In contrast, if all licensing agreements are negotiated bilaterally, without the guidance of a licensing model, royalty stacking may raise the cost of technology to the point where these conditions no longer exist.

For the broad deployment of the Principle of Proportionality, further research is needed to analyze mechanisms for determining and sharing the value of the technologies that are embodied in the end product. Ideally, such mechanisms should be transparent and follow the principles of FRAND. There are also close connections to various methods of market analysis: for example, the end users could be requested to evaluate different combinations of technologies and estimate how different technologies contribute to customer-perceived value.

\section{References}

Andrews, L., Paradise, J., Holbrook, T., Bochneak, D., Dec. 2006. When patents threaten science. Science 314, 1395-1396.

Arora, A., Fosfuri, A., Gambardella, A., 2001. Markets for Technology: The Economics of Innovation and Corporate Strategy. MIT Press. 
Başar, T., Olsder, G. J., 1982. Dynamic Noncooperative Game Theory. Academic Press.

Bass, F. M., 1969. A new product growth model for consumer durables. Management Science 15 (5), 215-227.

Bekkers, R., Duysters, G., Verspagen, B., Sep. 2002. Intellectual property rights, strategic technology agreements and market structure: the case of GSM. Research Policy 31 (7), $1141-1161$.

Blind, K., Thumm, N., Dec. 2004. Interrelation between patenting and standardisation strategies: empirical evidence and policy implications. Research Policy 33 (10), 15831598.

Calderini, M., Giannaccari, A., Sep. 2006. Standardisation in the ICT sector: The (complex) interface between antitrust and intellectual property. Economics of Innovation and New Technology 15 (6), 543-567.

Dolmans, M., Apr. 2002. Standards for standards. Paper for American Bar Association, Section of Antitrust Law, Spring meeting, accessed 27 June 2007.

URL http://www . abanet.org/antitrust/committees/intell_property/dolmans.pdf

ETSI, Nov. 2006a. ETSI guide on intellectual property rights (IPRs). Version endorsed by General Assembly \#48 on 22 November 2006, the European Telecommunications Standards Institute, accessed 27 June 2007.

URL http://www.etsi.org/legal/documents/ETSI_Guide_on_IPRs.pdf

ETSI, Nov. 2006b. ETSI IPR policy. Extracted form the ETSI Rules of Procedure, 22 November 2006, the European Telecommunications Standards Institute, accessed 27 June 2007.

URL http://www.etsi.org/legal/documents/ETSI_IPRPolicy.pdf

Frain, T., 2006. Patents in standards \& interoperability. World Intellectual Property Organization, 29 November 2006, accessed 27 June 2007.

URL http://www . wipo.int/patent/colloquia/en/2006/11/pdf/frain_paper.pdf

Gandal, N., Salant, D., Waverman, L., June-July 2003. Standards in wireless telephone networks. Telecommunications Policy 27 (5-6), 325-332.

Goodman, D. J., Myers, R. A., 2005. 3G cellular standards and patents. In: International Conference on Wireless Networks, Communications and Mobile Computing, 13-16 
June 2005. IEEE, pp. 415-420.

Goodman, D. J., Myers, R. A., Jul. 2007. Analysis of patents declared as essential to gsm as of june 6, 2007. Fairfield Resources International, accessed 31 August 2007. URL http://www.frlicense.com/GSM_7-5-2007.pdf

Greenhalgh, C., Rogers, M., 2006. The value of innovation: The interaction of competition, R\&D and IP. Research Policy 35 (4), 562-580.

Grindley, P. C., Teece, D. J., 1997. Managing intellectual capital: Licensing and crosslicensing in semiconductors and electronics. California Management Review 39 (2), $8-41$.

Hall, B. H., Griliches, Z., Hausmann, J. A., 1986. Patents and R and D: Is there a lag? International Economic Review 27 (2), 265-283.

Hall, B. H., Ziedonis, R. H., 2001. The patent paradox revisited: An empirical study of patenting in the US semiconductor industry, 1979-1995. The Rand journal of economics 32 (1), 101-128.

Hardin, G., Dec. 1968. The tragedy of the commons. Science 168, 1243-1248.

Heller, M. A., Jan. 1998. The tragedy of the anticommons: Property in the transition from Marx to markets. Harvard Law Review 111 (3), 621-688.

Heller, M. A., Eisenberg, R. S., May 1998. Can patents deter innovation? The anticommons in biomedical research. Science 280, 698-701.

Infonetics Research, 2007. Radio access network equipment 4Q06/CY06 market share \& forecast.

URL http://www.infonetics.com/

Kalai, E., Oct. 1977. Proportional solutions to bargaining situations: Interpersonal utility comparisons. Econometrica 45 (7), 1623-1630.

Kunc, M. H., Morecroft, J. D. W., Sep. 2007. Competitive dynamics and gaming simulation: lessons from a fishing industry simulator. Journal of the Operational Research Society 58 (9), 1146-1155.

Lemley, M. A., Shapiro, C., 2005. Probabilistic patents. The Journal of Economic Perspectives 19 (2), 75-98.

Lemley, M. A., Shapiro, C., 2007. Patent holdup and royalty stacking. Texas Law Review 
85, 1991-2049.

Lin, B.-W., Lee, Y., Hung, S.-C., 2006. R\&D intensity and commercialization orientation effects on financial performance. Journal of Business Research 59 (6), 679-685.

Megantz, R. C., 2002. Technology Management: Developing and Implementing Effective Licensing Programs. John Wiley \& Sons.

Nash, J., 1951. Non-cooperative games. Annals of Mathematics 54 (2), 286-295.

Roth, A. E., May 1979. Proportional solutions to the bargaining problem. Econometrica $47(3), 775-778$.

Salmenkaita, J.-P., Salo, A., 2002. Rationales for government intervention in the commercialization of new technologies. Technology Analysis \& Strategic Management 14 (2), $183-200$.

Salmenkaita, J.-P., Salo, A., 2004. Emergent foresight processes: industrial activities in wireless communications. Technological Forecasting and Social Change 71, 897-912.

Scherer, F. M., 1965. Corporate inventive output, profits, and growth. Journal of Political Economy 73 (3), 290-297.

Shapiro, C., 2001. Navigating the patent thicket: Cross licenses, patent pools, and standard setting. In: Jaffe, A. B., Lerner, J., Stern, S. (Eds.), Innovation Policy and the Economy. Vol. 1. MIT Press, pp. 119-150.

Shapiro, C., Aug. 2006. Injunctions, hold-up, and patent royalties. Manuscript, accessed 27 June 2007.

URL http://faculty.haas.berkeley.edu/shapiro/royalties.pdf

Smits, R., Kuhlmann, S., 2004. The rise of systemic instruments in innovation policy. International Journal of Foresight and Innovation Policy 1 (1/2), 4-32.

Sterman, J. D., 2000. Business Dynamics: Systems Thinking and Modeling for a Complex World. McGraw-Hill.

Sterman, J. D., 2001. System dynamics modeling: Tools for learning in a complex world. California Management Review 43 (4), 8-25.

Strategy Analytics, May 2007. Vendor share: Global handset market update: Q1 2007. URL http://www.strategyanalytics.net/

Takalo, T., Kanniainen, V., 2000. Do patents slow down technological progress? Real 
options in research, patenting, and market introduction. International Journal of Industrial Organization 18 (7), 1105-1127.

Teece, D. J., 1986. Profiting from technological innovation: implications for integration, collaboration, licensing and public policy. Research Policy 15, 285-305.

Teece, D. J., 2000. Managing Intellectual Capital. Oxford University Press.

Thomson, W., 2003. Axiomatic and game-theoretic analysis of bankruptcy and taxation problems: a survey. Mathematical Social Sciences 45, 249-297.

Thumm, N., Dec. 2005. Patents for genetic inventions: a tool to promote technological advance or a limitation for upstream inventions. Technovation 25 (12), 1410-1417.

West, J., Jul. 2003. How open is open enough? Melding proprietary and open source platform strategies. Research Policy 32 (7), 1259-1285.

Ziedonis, R. H., Jun. 2004. Dont fence me in: Fragmented markets for technology and the patent acquisition strategies of firms. Management Science 50 (6), 804-820. 


\section{A Variables}

\section{Variable Description}

$\gamma_{P C}(t) \quad$ Relative strength of PC's technology portfolio

$\gamma_{P M C}(t) \quad$ Relative strength of PMC's technology portfolio

$\delta_{M C}(t) \quad$ MC manufacturing activity indicator

$\delta_{P M C}(t) \quad$ PMC manufacturing activity indicator

$\tilde{\delta}_{M C}(t) \quad$ MC market entry decision indicator

$\tilde{\delta}_{P M C}(t) \quad$ PMC market entry decision indicator

$\pi_{M C}(t) \quad$ MC net cash flow per month

$\pi_{P C}(t) \quad$ PC net cash flow per month

$\pi_{P M C}(t) \quad$ PMC net cash flow per month

$c_{M C}(t) \quad$ MC costs of manufacturing per month

$c_{P C}(t) \quad \mathrm{PC}$ costs R\&D per month

$c_{P M C}(t) \quad$ PMC costs of manufacturing and R\&D per month

$s_{M C}(t) \quad$ MC product sales per month

$s_{P M C}(t) \quad$ PMC product sales per month

$t_{M C} \quad$ MC market entry time

$t_{P M C} \quad$ PMC market entry time

$C(t) \quad$ Cumulative buyers of product

$P(t) \quad$ Potential new customers

$T_{P C}(t) \quad$ PC's cumulative technology portfolio

$T_{P M C}(t) \quad$ PMC's cumulative technology portfolio 


\section{B Parameters}

$\begin{array}{lrl}\text { Parameter } & \text { Value } & \text { Description } \\ \beta_{a d v} & 0.01 & \text { Effect of advertising on sales } \\ \beta_{\text {imit }} & 10^{-8} & \text { Effect of imitative behavior on sales } \\ \beta_{\text {tech }}(T) & & \text { Impact of cumulative technology development on sales (see Figure 4) } \\ \tau_{M C} & 12 & \text { MC delay between market entry decision and market entry } \\ \tau_{P M C} & 3 & \text { PMC delay between market entry decision and market entry } \\ \tau_{P L C} & 24 & \text { Product life cycle length parameter } \\ \tau_{T L C} & 120 & \text { Technology life cycle length parameter } \\ f & 1.6 \cdot 10^{6} & \text { Monthly fixed costs of product manufacturing } \\ i_{P C} & 5 \cdot 10^{5} & \text { PC monthly R\&D investment expenditures } \\ i_{P M C} & 8 \cdot 10^{5} & \text { PMC monthly R\&D investment expenditures } \\ m & 0.75 & \text { Single manufacturer market utilization } \\ \Delta m & 0.25 & \text { Decrease in market utilization due to other manufacturer market entry } \\ p & 160 & \text { Product price } \\ r_{M C} & 0.15 & \text { Discount rate for MC } \\ r_{P C} & 0.12 & \text { Discount rate for PC } \\ r_{P M C} & 10^{6} & \text { PC's cumulative technology portfolio at time } t=0 \\ u & 10^{6} & \text { PMC's cumulative technology portfolio at time } t=0 \\ C(0) & 0.20 & \text { Discount rate for PMC } \\ P(0) & \text { Manufacturing cost per product } & \text { Customers at time } t=0 \\ & 10^{7} & \text { Potential customers at time } t=0 \\ & & \end{array}$


C Model causal diagram

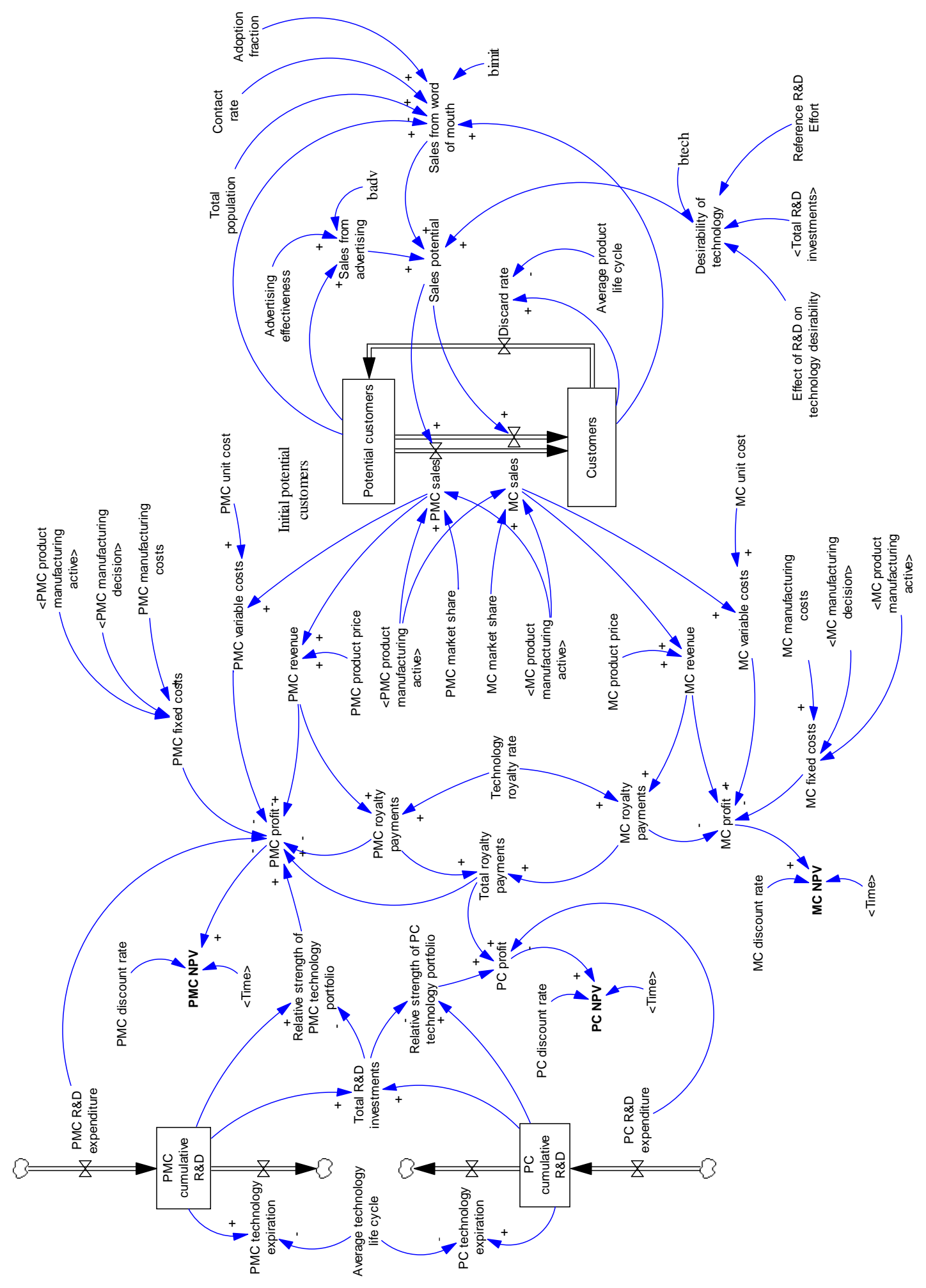


Figure 1

$\begin{aligned} & \text { Technological } \\ & \text { value } \\ & \text { value }\end{aligned}$
Other values


Figure 2

Product manufacturers' optimal market entry time

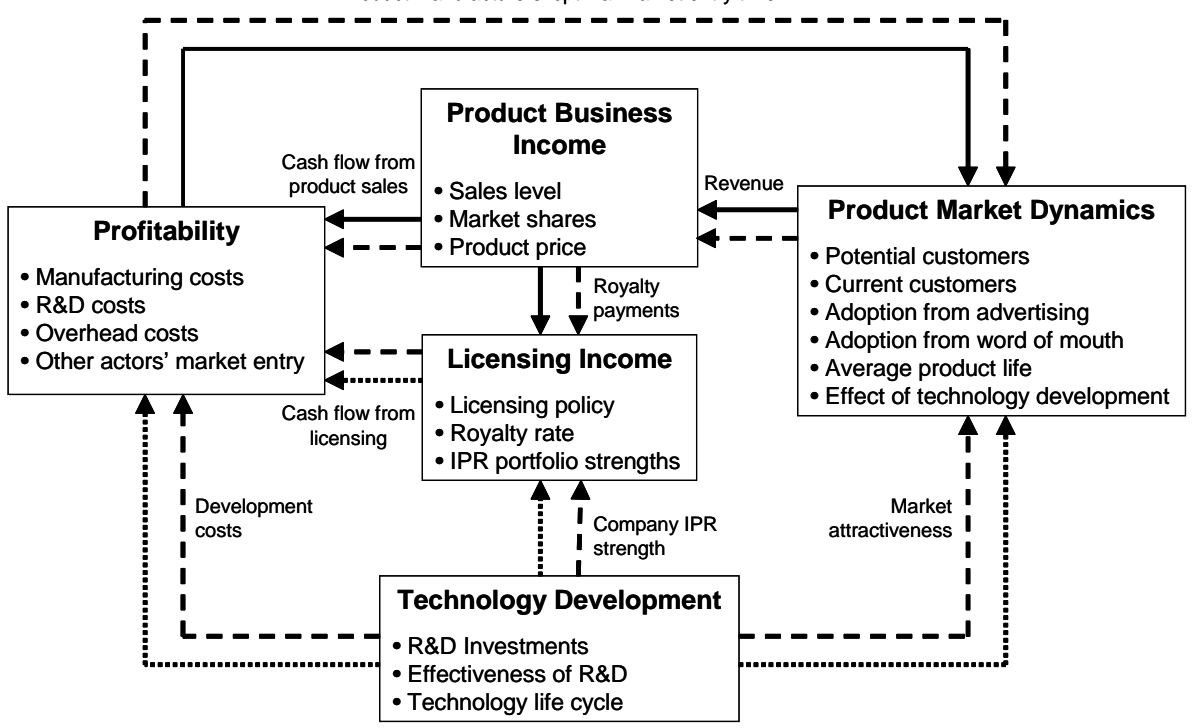

Manufacturing Company (MC)

- - - - Patenting and Manufacturing Company (PMC)

.......... Patenting Company (PC) 
Figure 3

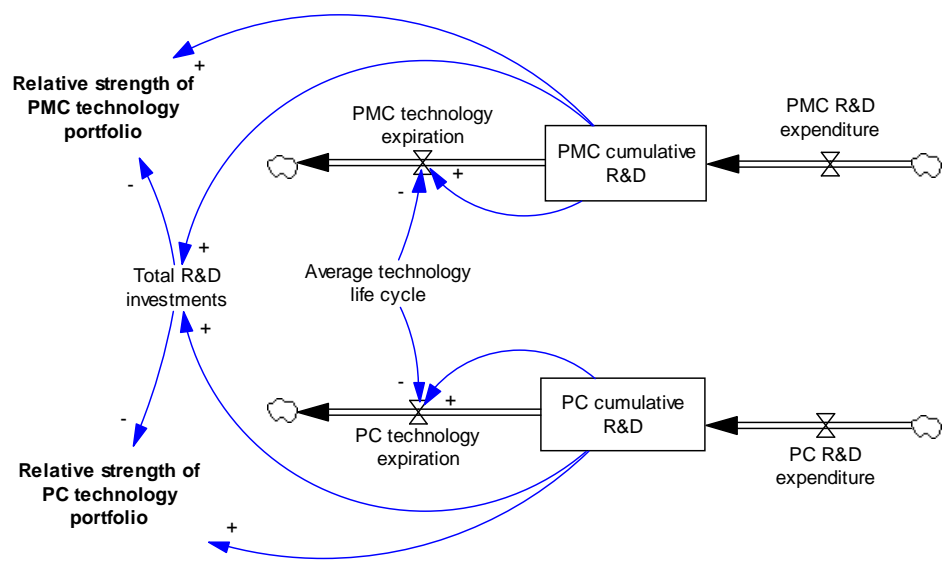


Figure 4

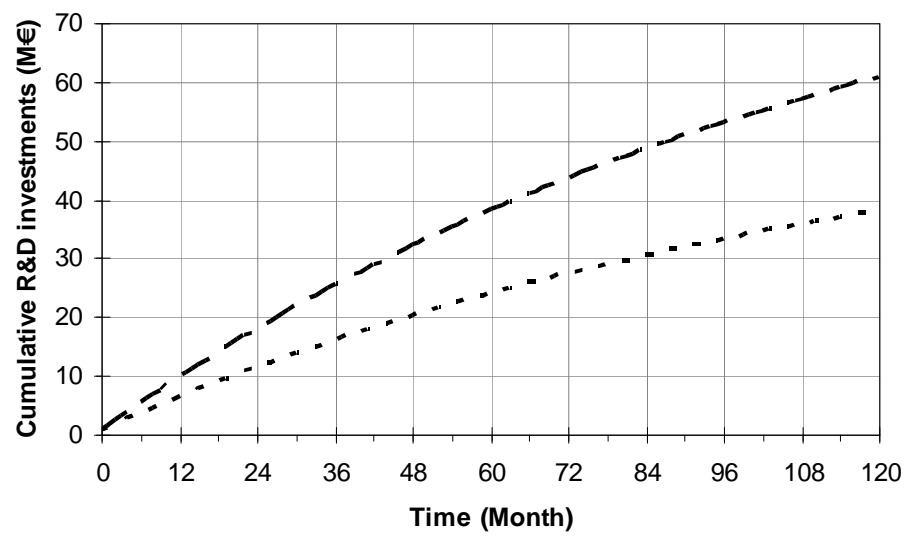

- - PMC cumulative R\&D

- - - PC cumulative R\&D

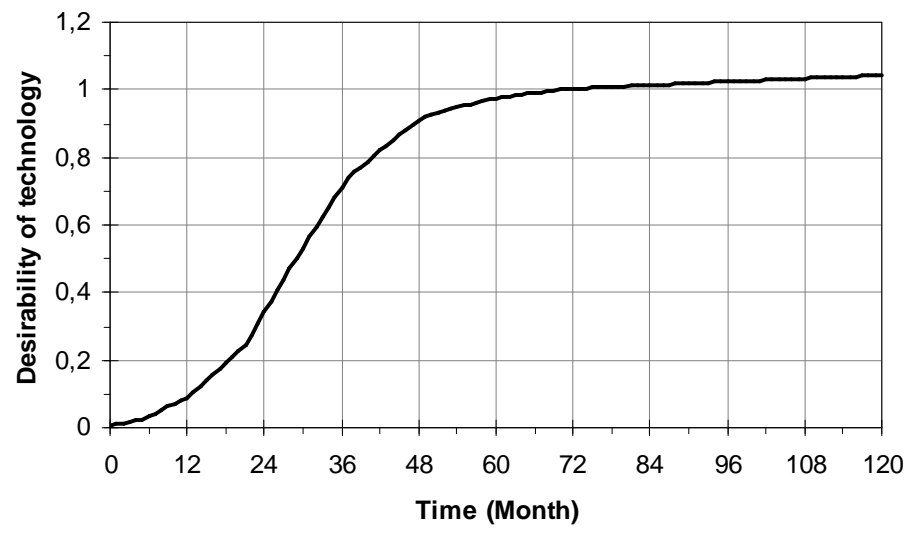


Figure 5

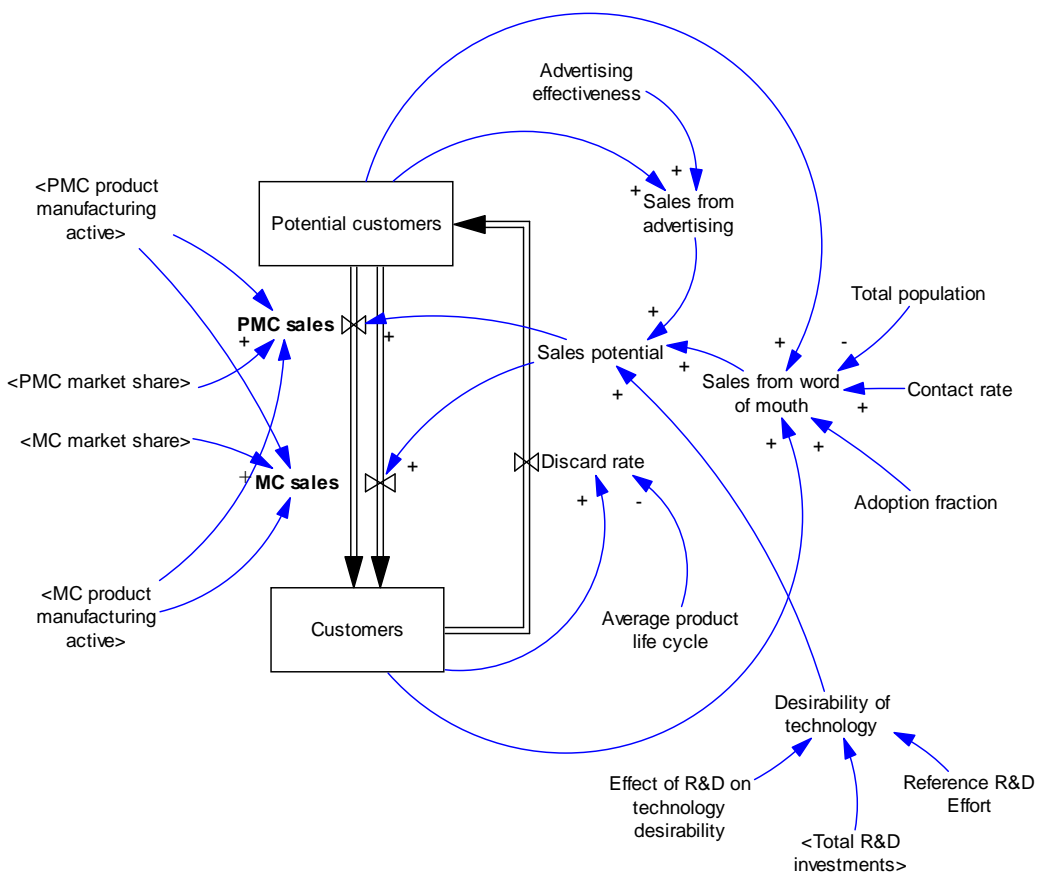




\section{Figure 6}
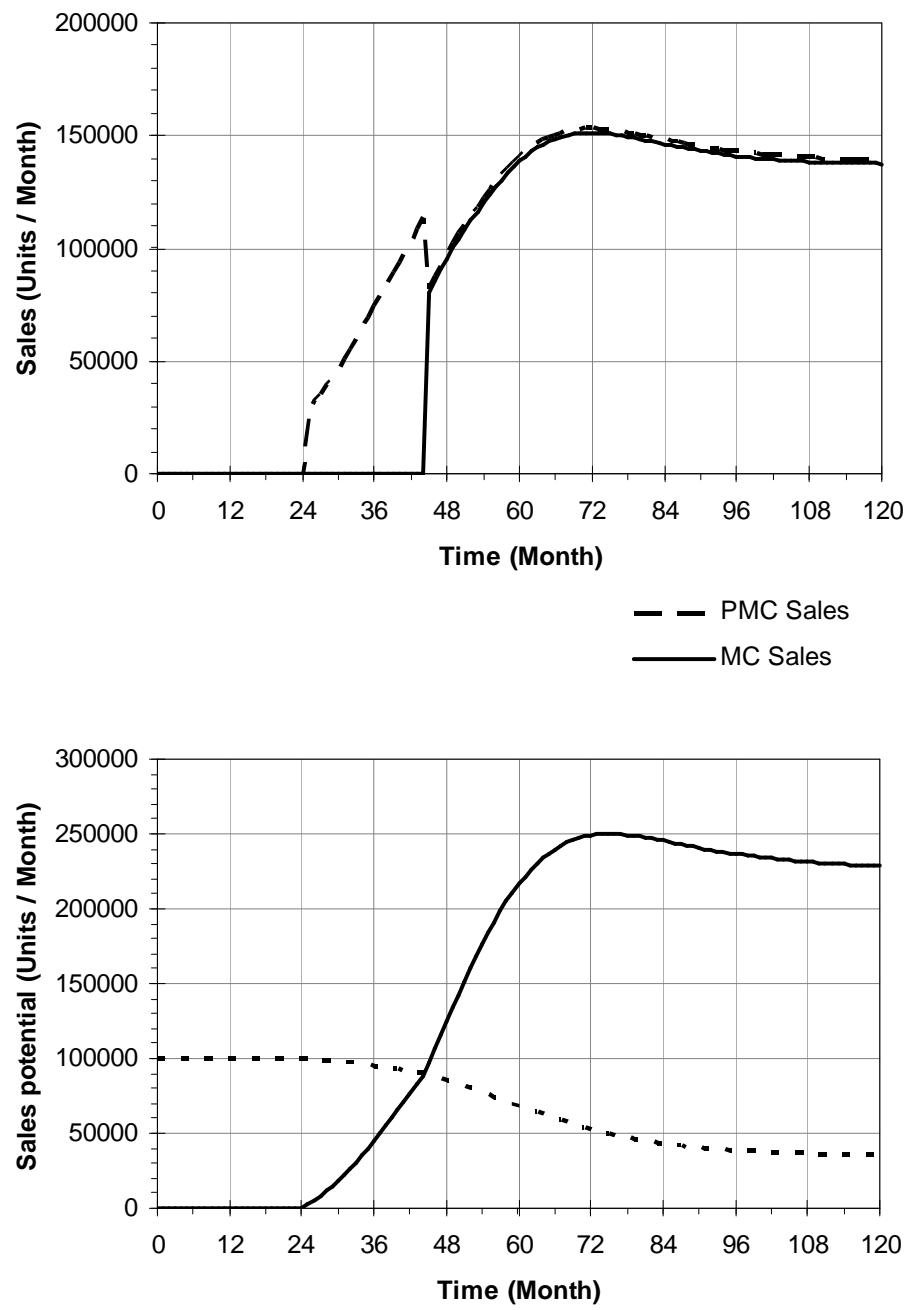

- - - Sales potential from advertising -Sales potential from word of mouth 


\section{Figure 7}

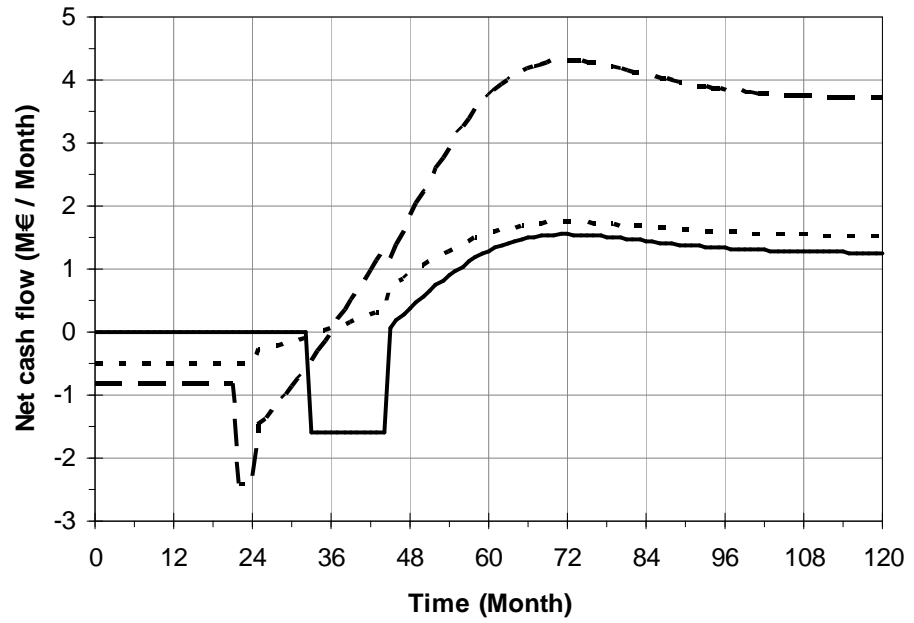

Manufacturing Company (MC)

- Patenting and Manufacturing Company (PMC)

- - - - Patenting Company (PC) 
Figure 8
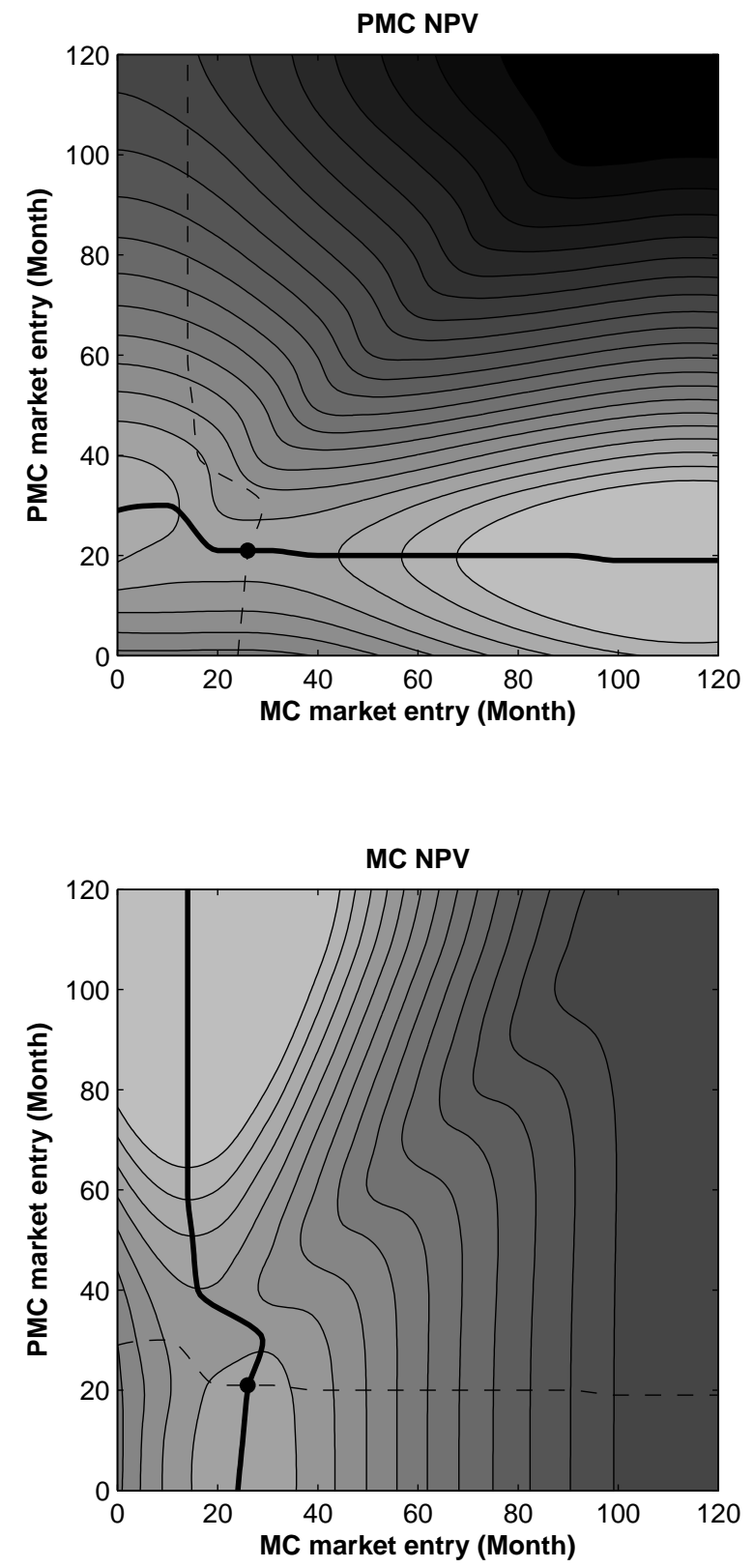
Figure 9

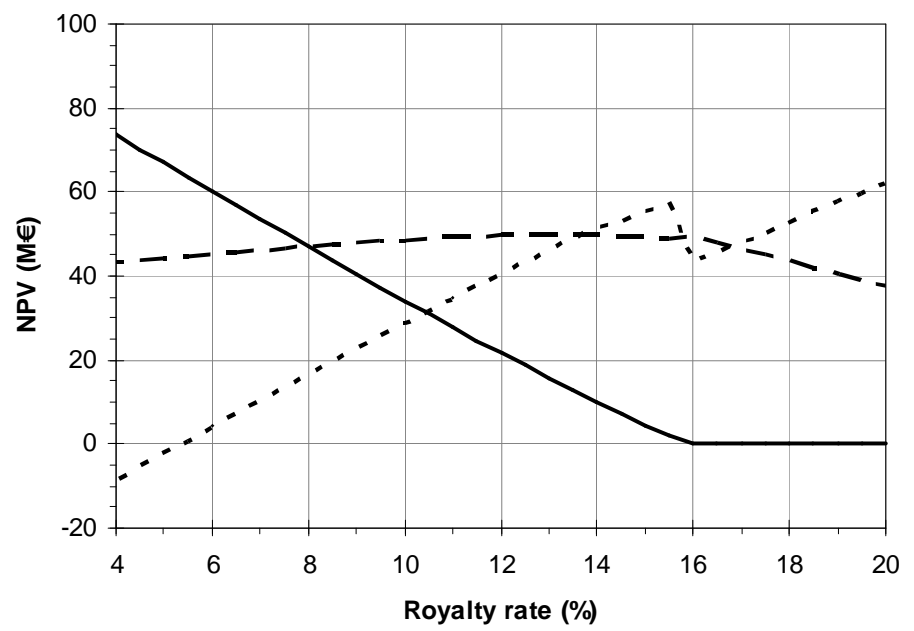

-Manufacturing Company (MC)

- Patenting and Manufacturing Company (PMC) - . - Patenting Company (PC) 
Figure 10

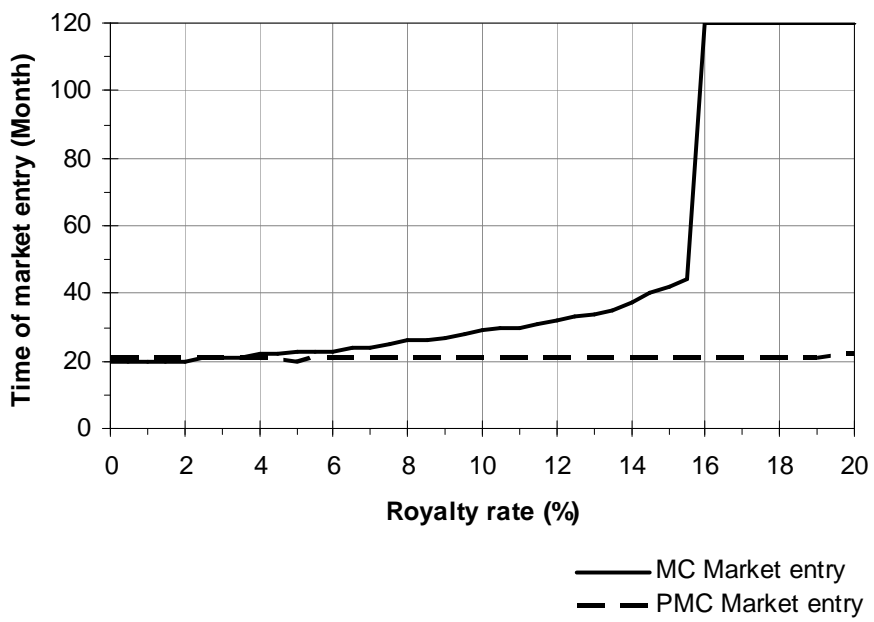


Figure 11

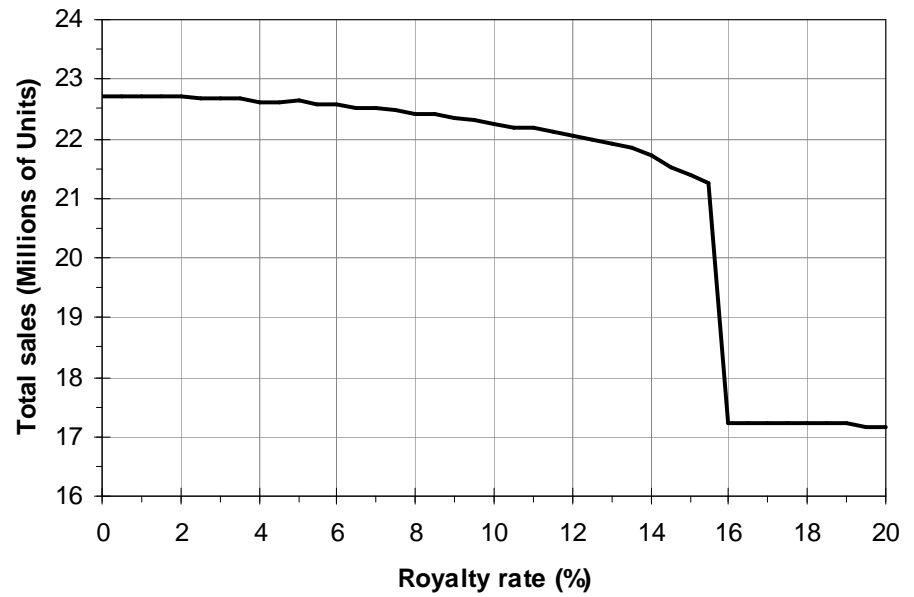


Figure 12

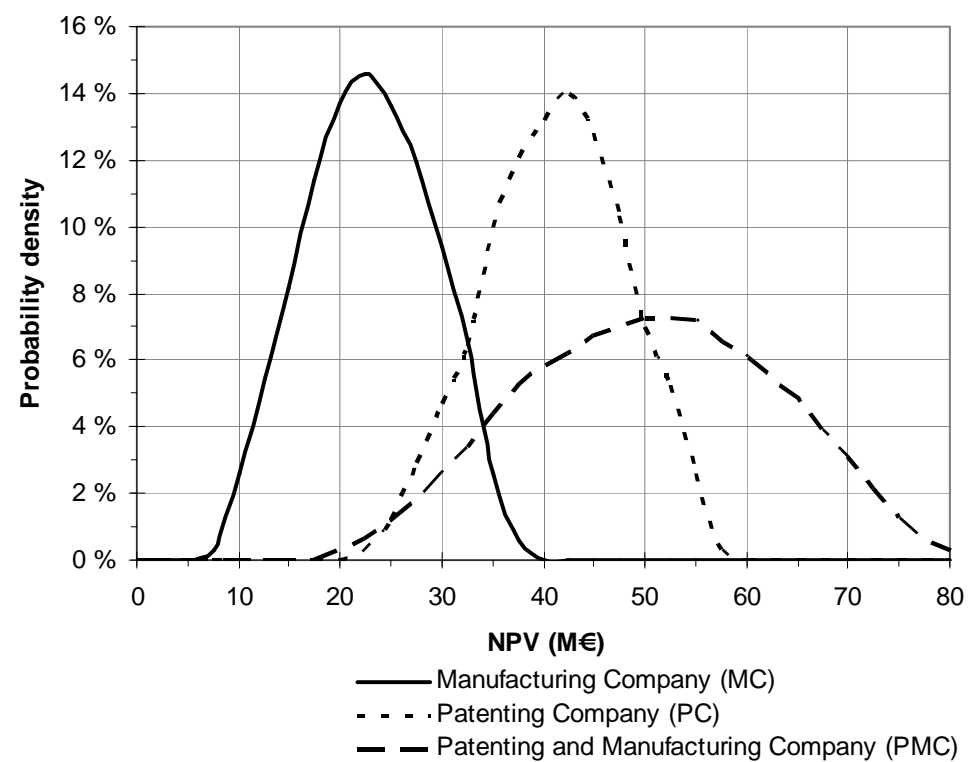




\section{Figure captions}

Figure 1. Royalty payments in the Principle of Proportionality

Figure 2. Structure of the model

Figure 3. The dynamics of the relative strengths of technology portfolios

Figure 4. Cumulative R\&D investments for PC $T_{P C}(t)$ and PMC $T_{P M C}(t)$ (above) and desirability of technology in the product markets $\beta_{\text {tech }}\left(T_{P C}(t)+T_{P M C}(t)\right)$ (below)

Figure 5. Product market dynamics of the model

Figure 6. Sales components from advertising $\beta_{a d v} P(t)$ and imitation $\beta_{\text {imit }} P(t) C(t)$ (above) and actual sales for MC $s_{M C}(t)$ and PMC $s_{P M C}(t)$ (below)

Figure 7. Simulated net cash flows $\pi_{P M C}(t), \pi_{M C}(t)$ and $\pi_{P C}(t)$

Figure 8. NPV contours and market entry reaction curves of PMC and MC with $8 \%$ royalty rate

Figure 9. Companies' NPVs as a function of technology royalty rate $\xi$

Figure 10. Effect of technology royalty rate $\xi$ on the time of market entry of PMC and MC

Figure 11. Effect of royalty rate $\xi$ on total cumulative sales on the market

Figure 12. Probability distributions of NPVs of companies with uniform distributions $[0.9 \beta, 1.1 \beta]$ for $\beta_{a d v}, \beta_{\text {imit }}$, and $\beta_{\text {tech }}$ 
Table 1

UMTS technology market shares (Strategy Analytics, 2007; Infonetics Research, 2007) and patent ownership of 3GPP judged essential patents (Goodman and Myers, 2005)

\begin{tabular}{|c|c|c|c|c|}
\hline Company & $\begin{array}{l}\text { Handset market- } \\
\text { share Q4'06 (\%) }\end{array}$ & $\begin{array}{l}\text { Network market- } \\
\text { share Q4'06 (\%) }\end{array}$ & $\begin{array}{l}\text { UMTS patent } \\
\text { ownership (\%) }\end{array}$ & Category \\
\hline Alcatel ${ }^{a}$ & & 9 & 3 & \\
\hline $\begin{array}{l}\text { Ericsson \& } \\
\quad \text { Sony Ericsson }\end{array}$ & 20 & 43 & 22 & \\
\hline Mitsubishi & 1 & & 3 & \\
\hline Motorola & 5 & 3 & 7 & $\mathrm{PMC}$ \\
\hline Nokia ${ }^{b}$ & 33 & 17 & 24 & \\
\hline NTT DoCoMo ${ }^{c}$ & & & 3 & \\
\hline $\begin{array}{l}\text { Panasonic } \\
\text { (Matsushita) }\end{array}$ & 4 & & 2 & \\
\hline Qualcomm d & & & 19 & \\
\hline Siemens b & & 11 & 5 & \\
\hline Huawei & & 4 & & \\
\hline LG & 6 & & & \\
\hline NEC & 4 & 7 & & \\
\hline Sagem & $<1$ & & & $\mathrm{MC}$ \\
\hline Samsung & 8 & 3 & & \\
\hline Sharp & 8 & & & \\
\hline TCL & $<1$ & & & \\
\hline Hitachi & & & 3 & \\
\hline Interdigital & & & 3 & $\mathrm{PC}$ \\
\hline Philips & & & 3 & \\
\hline Others & 10 & 3 & 3 & \\
\hline \multicolumn{5}{|c|}{ a Network business later in Alcatel-Lucent } \\
\hline \multicolumn{5}{|c|}{ b Network business later in Nokia Siemens Networks } \\
\hline${ }^{\mathrm{c}}$ Uses the techno & ogy as operator & & & \\
\hline${ }^{\mathrm{d}}$ Uses the techno & ogy in chipset bus & & & \\
\hline
\end{tabular}

